\title{
PENGARUH VARIASI PRODUK TERHADAP KEPUTUSAN PEMBELIAN BAHAN BANGUNAN DI PORTAL NETWORK SIX STORE Cabang DEPOK 2018
}

\author{
Wahyu Nurul Faroh *) \\ dosen01061@unpam.ac.id \\ Defri Junaidi*)
}

\begin{abstract}
ABSTRAK
Penelitian ini bertujuan untuk mengetahui bagaimana pengaruh variasi produk terhadap keputusan pembelian pada Portal Network cabang

Metode penelitian yang digunakan adalah metode penelitian deskriftif kuantitatif, dimulai dari pengumpulan data, penafsiran data tersebut, serta penampilan dari hasil yang bersifat data, melalui penyebaran angket (kuesioner) yang berisi 10 pernyataan yang terkait dengan variable variasi produk $(\mathrm{X})$ dan 10 pernyataan terkait dengan varibel keputusan pembelian (Y) yang disebarkan kepada 98 responden yang merupakan pelanggan toko bangunan portal network six store cabang Depok. Data yang diperoleh dari penyebaran kuesioner dianalisis menggunakan beberapa tahapan pengujian yaitu uji validitas, uji reliabilitas, uji korelasi, uji koefisien determinasi, uji regresi linier sederhana, dan uji signifikan (uji t).

Hasil dari penelitian menunjukan bahwa terdapat pengaruh yang kuat antara variasi produk terhadap keputusan pembelian yang ditunjukan oleh $r$ sebesar 0,6458 . Koefisien determinasi menunjukan bahwa pengaruh variasi produk terhadap keputusan pembelian sebesar $41,71 \%$, sedangkan sisanya sebesar $58,29 \%$ dipengaruhi oleh faktor-faktor lain yang tidak diteliti. Analisis regresi linier sederhana sebesar $Y=31,7+0,5080 X$. Sedangkan uji signifikan (uji t) yaitu nilai thitung $>$ ttabel $(8,2875>1,66088)$, maka $\mathrm{H}_{0}$ ditolak dan $\mathrm{H}_{\mathrm{a}}$ diterima. Dengan demikian, bahwa terdapat pengaruh positif dan signifikan antara variasi produk terhadap keputusan pembelian pada Portal network six store cabang Depok.
\end{abstract}

Kata Kunci : Variasi produk dan Keputusan pembelian

\begin{abstract}
This study aims to determine how the effect of product variation on purchasing decisions on Depok branch portal network

The research method used is quantitative descriptive research method, starting from data collection, interpretation of the data, as well as the appearance of results that are data in nature, through questionnaires (questionnaires) containing 10 statements related to variable product variations $(\mathrm{X})$ and 10 statements related to purchasing decision variables $(\mathrm{Y})$ distributed to 98 respondents who are customers of the Depok branch six store network portal store. Data obtained from questionnaires were analyzed using several stages of testing namely validity test, reliability test, correlation test, coefficient of determination test, simple linear regression test, and significant test (t test).

The results of the study show that there is a strong influence between product variations on purchasing decisions as indicated by $r$ of 0.6458 . The coefficient of determination shows that the effect of product variation on purchasing decisions is $41.71 \%$, while the remaining $58.29 \%$ is influenced by other factors not examined. Simple linear regression analysis of $Y=31.7+0.5080 \mathrm{X}$. While the significant test ( $\mathrm{t}$ test) is the value of tcount $>\mathrm{t}$ table $(8.2875>1.66088)$, then $\mathrm{Ho}$ is rejected and $\mathrm{Ha}$ is accepted. Thus, there is a positive and significant influence between product variations on purchasing decisions in the Depok branch of the six store network portal.
\end{abstract}

Keywords: Product variations and purchasing decisions 


\section{PENDAHULUAN}

\section{A. Latar Belakang Masalah}

Perusahaan Portal Network Six Store cabang Depok adalah perusahaan yang bergerak pada bidang penjualan alat bahan banguaan yang di sasarkan kepada pasar tradisional, yang menjadi bahan penelitian penulis adalah pilihan barang masih kurang bervariasi baik dari ukuran, harga maupun tampilan, perusahaan perlu mengembangkan secara berkesinambungan seiring dengan perubahan kebutuhan dan keinginan konsumen yang senantiasa berubah.

Berdasarkan fenomena dan pendapat diatas, maka Penulis akan meneliti "Pengaruh Variasi Produk Terhadap Keputusan Pembelian Bahan bangunan Portal Portal Network Six Store Cabang Depok"

\section{B. Perumusan Masalah}

Seberapa besar pengaruh variasi produk terhadap keputusan pembelian bahan bangunan di portal network six store?

\section{Tujuan Penelitian}

Untuk mengetahui pengaruh variasi produk terhadap keputusan pembelian bahan bangunan di portal network six store

\section{Landasan Teori}

\section{Variasia produk}

Variasi produk merupakan suatu proses menciptakan suatu produk yang beragam baik dari ukuran, harga maupun tampilannya, perusahaan perlu mengembangkan variasi produk secara berkesinambungan seiring dengan dengan perubahan kebutuhan dan keinginan konsumen yang senantiasa berubah.

Menurut Philip Kotler (2009:72), "variasi produk sebagai ahli tersendiri dalam suatu merek atau lini produk sebagai lini produk yang dapat dibedakan berdasarkan ukuran, harga penampilan atau ciri-ciri”. Sedangkan menurut Mikel P.Groover (2010:6) menyatakan bahwa "variasi produk dapat diartikan sebagai produk yang memiliki desain atau jenis yang berbeda dan diproduksi 
oleh sebuah pabrik, perbedaan produk mencakup perbedaan bentuk dan ukuran"

indikator Variasi produk menurut Fandi Tjiptono (2009:97) terdiri dari ukuran, harga, tampilan dan bahan bahan.
a. Ukuran
b. Harga
c. Tampilan
d. Bahan-bahan

\section{Keputusan Pembelian}

Tujuan utama dari serangakaian proses pemasaran adalah aktivitas pembelian yang dilakukan oleh konsumen, konsumen sebagai pelaku utama dalam proses pembelian selalu menjadi perhatian produsen, produsen , produsen kini banyak yang perhatian khusus kepada konsumen, terutama dalam mempelajari prilaku konsumen, dalam proses yang bersifat dinamis. Menurut Kotler \& Amstrong (2009:227)“keputusan pembelian adalah tahap proses keputusan dimana konsumen secara aktual melakukan pembelian prdouk”. dan menurut Kawee Boonelertvanich dalam jurnal “Consumer buying dan Decision Marketing Behavior of a Digital camera in Thailand" (2009:57) "Perilaku konsumen merupakan proses keputusan dan serankaian tindakan manusia dalam membeli dan menggunakan produk, keputusan pembelian diefinisikan sebagai pola prilaku konsumen yang memperoses, memutuskan dan mengikuti hasil proses keputusan tersebut untuk memenuhi kebutuhan dengan produk, die atau jasa".

Indikator keputusan pembelian menurut, Kotler dan Keller (2009:202) terdiri dari pilihan produk, pilihan merek, pilihan penyalur, jumlah pembelian, dan waktu pembelian

1. Pilihan Produk

2. Pilihan Merek

3. Pilihan Penyalur

4. Jumlah Pembelian

5. Waktu Pembelian 


\section{E. METODE PENELITIAN}

Populasi dalam penelitian ini adalah konsumen toko bangunan Portal Network Six Store cabang Depok, Populasi 2507, Sampel diamil menggunakan rumus teknik slovin (Husein Umar, 2008: 52)

$n=\frac{N}{1+N e^{2}}$

Dimana :

$\mathrm{n}=$ Jumlah Sampel

$\mathrm{N}$ = Jumlah Populasi

1 = Konstanta

e $=$ Standar erorr yaitu $10 \%$

Berdasarkan rumus tersebut didapat besar sampel sebagai berikut :

$N=2.507$

1 = Konstanta

e $=10 \%$ atau 0,1

maka dapat di hitung :

$n=\frac{2.507}{1+2.500(0,1)^{2}}$

$n=\frac{2.507}{31,8}$

$n=96,15$

$n=98$

\section{Metode Analisis data}

1. Uji Validitas

$$
r=\frac{n \Sigma \mathrm{X} . \mathrm{Xt}-\Sigma \mathrm{X} \Sigma \mathrm{Xt}}{\sqrt{\left[n \Sigma x^{2}-(\Sigma x)^{2}\right]\left[n \Sigma \mathrm{X} \mathrm{t}^{2}-(\Sigma \mathrm{Xt})^{2}\right]}}
$$

$\mathrm{r}=$ Koefisien korelasi

$\mathrm{N}=$ Jumlah responden 
$\Sigma \mathrm{X}=$ Total skor butir penyataan

$\Sigma \mathrm{Xt}=$ Total skor butir pernyataan

$\Sigma X^{2}=$ Jumlah kuadrat skor $X$

$\Sigma X t^{2}=$ Jumlah kuadrat skor $Y$

\section{Uji Reliabilitas}

$$
\mathrm{r}=\left(\frac{K}{K-1}\right)\left(1-\frac{\Sigma S i}{S t}\right)
$$

Dimana:

$r \quad=$ koefisien realibilitas instrumen (Alfa cronbach)

$\Sigma \mathrm{Si}=$ skor varian butir pernyataan

St = skor varian total pernyataan

$\mathrm{K}$ = bayaknya item kuesioner

\section{Koefisien Korelasi}

Dimana :

$$
r_{x y}=\frac{n \Sigma X . Y-(\Sigma X)(\Sigma Y)}{\sqrt{\left\{n \Sigma X^{2}-(\Sigma X)^{2}\right\}-\left\{n \Sigma Y^{2}-(\Sigma Y)^{2}\right\}}}
$$

Keterangan :

rxy $\quad=$ Koefisien korelasi

$\mathrm{n} \quad=$ Jumlah responden

$\Sigma \mathrm{X}=$ Total skor butir penyataan

$\Sigma Y=$ Total skor butir pernyataan

$\sum X^{2}=$ Jumlah kuadrat skor $X$

$\sum Y^{2}=$ Jumlah kuadrat skor $Y$

\section{Koefisien Determinasi}

$$
\mathrm{KD}=\mathrm{r}^{2} \times 100 \%
$$

Dimana :

$\mathrm{KD}=$ koefisien determinasi

$\mathrm{r}^{2}=$ koefisien korelasi $\mathrm{X}$ dan $\mathrm{Y}$

$\widehat{\mathrm{Y}}=\mathrm{a}+\mathrm{bX}$

Keterangan :

$\mathrm{Y} \quad=$ Variabel dependen $\mathrm{Y}$ (nilai yang diprediksikan) 
$\mathrm{X}=$ Variabel independen

a = Konstanta (nilai $Y^{\prime}$ apabila $X=0$ )

b = Koefisien regresi

Dimana :

$$
\begin{aligned}
\mathrm{b} & =\frac{\mathrm{n}(\Sigma \mathrm{XY})-(\Sigma \mathrm{X})(\Sigma \mathrm{Y})}{\mathrm{n}\left(\Sigma \mathrm{X}^{2}\right)-(\Sigma \mathrm{X})^{2}} \\
\mathrm{a} & =\frac{\Sigma \mathrm{Y}-\mathrm{b}(\Sigma \mathrm{X})}{\mathrm{n}}
\end{aligned}
$$

Uji Hipotesis (Uji-t)

$$
\mathrm{t}=\frac{\mathrm{r} \sqrt{\mathrm{n}-2}}{\sqrt{1-\mathrm{r}^{2}}}
$$

Keterangan :

$\mathrm{t}=$ nilai $\mathrm{uji} \mathrm{t}$

$r=$ koefisien korelasi

$\mathrm{n}$ = banyaknya sampel

Dengan perumusan hipotesisnya adalah :

\section{F. HASIL PENELITIAN DAN PEMBAHASAN}

a) Regresi Linier Sederhana

Diketahui :

$$
\begin{aligned}
& N \quad=98 \\
& \Sigma X \quad=4005 \\
& \Sigma Y \quad=4162 \\
& \Sigma X^{2}=165073 \\
& \Sigma Y^{2} \quad=177624 \\
& \Sigma X Y=170801 \\
& a=\frac{\left(\sum Y\right)\left(\sum X^{2}\right)-\left(\sum X\right)\left(\sum X Y\right)}{n\left(\sum X^{2}\right)-\left(\sum X\right)^{2}} \\
& a=\frac{(4162)(165073)-(4005)(170801)}{98(165073)-(4005)^{2}} \\
& =\frac{687033826-684058005}{16177154-16040025} \\
& =\frac{2975821}{137129}
\end{aligned}
$$


$=21,7009$

$\mathrm{b}=\frac{n(\Sigma X Y)-(\Sigma X)(\Sigma Y)}{n \sum X^{2}-(\Sigma X)^{2}}$

$\mathrm{b}=\frac{98(170801)-(4005)(4162)}{98(177624)-(4005)^{2}}$

$\mathrm{b}=\frac{16738498-16668810}{17407152-16040025}$

$\mathrm{b}=\frac{69688}{1367172}$

$b=0.5080$

dari hasil perhitungan tersebut, diperoleh hasil perhitungan regresi sebagai berikut: $Y=21,7+0.5080 X$

\section{b) Koefisien Determinasi}

$K D=r^{2} \times 100 \%$

$\mathrm{KD}=0.6458^{2} \times 100 \%$

$\mathrm{KD}=0.4171 \times 100 \%$

$\mathrm{KD}=41.71 \%$

Hal ini membuktikan bahwa besarnya pengaruh variasi produk terhadap keputusan pembelian sebesar $41.71 \%$ dan sisanya $58.29 \%$ di pengaruhi oleh faktor lain yang peneliti tidak lakukan kerana keterbatasan waktu, tenaga dan biaya.

\section{c) Uji Hipotesis (Uji t)}

Berdasarkan perhitungan di atas, maka peneliti melakukan pengujian hipotesa dengan cara membandingkan nilai tabel dan

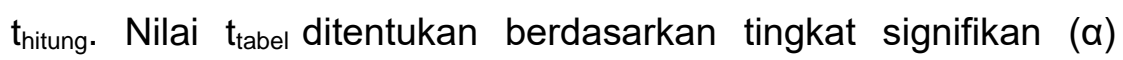
yang digunakan dan derajat kebebasan ( $\mathrm{df}=\mathrm{n}-2)$ yang besarnya tergantung dari jumlah sampel $(n)$. Taraf nyata yang penulis gunakan sebesar (10\%).

untuk mencari $t_{\text {tabel }}$ menggunakan rumus sebagai berikut:

$t_{\text {tabel }}=\mathrm{t}(\alpha / 2 ; n-k-1)=\mathrm{t}(0,10 ; 96)=1,66088$

Rumus $t_{\text {hitung }}$ sebagai berikut:

$t_{\text {hitung }}=\frac{r \sqrt{n-2}}{\sqrt{1-r^{2}}}$

Dimana:

$r=$ koefisien korelasi 


$$
\begin{aligned}
& \mathrm{n}=\text { jumlah responde/sampel } \\
& t_{\text {hitung }}=\frac{0,6458 \sqrt{98-2}}{\sqrt{1-0,6458^{2}}} \\
& =\frac{0,6458 \times 9,798}{\sqrt{1-0,4171}} \\
& =\frac{6,3275}{\sqrt{0,5829}} \\
& =\frac{6,3275}{0,7635} \\
& =8,2875 \\
& \text { Pengambilan keputusan menggunakan angkat } \\
& \text { pembanding } t_{\text {tabel }} \text { dengan kriteria sebagai berikut: } \\
& \text { jika } t_{\text {hitung }}>t_{\text {tabel }} H_{0} \text { ditolak; } H_{a} \text { diterima (signifikan) } \\
& \text { jika } t_{\text {hitung }}<t_{\text {tabel }} H_{0} \text { diterima; } H_{a} \text { ditolak (tidak signifikan) } \\
& \text { Sehingga berdasarkan hasil pengujian rumus di atas maka } \\
& t_{\text {hitung }}>t_{\text {tabel }} \text { yaitu } 8,2875>1,66088 \text { yang artinya bahwa } H_{0} \\
& \text { ditolak } \mathrm{H}_{\alpha} \text { diterima, dari hasil tersebut dapat disimpulakan variasi } \\
& \text { produk (X) mempunyai pengaruh yang signifikan terhadap } \\
& \text { keputusan pembelian }
\end{aligned}
$$

\section{KESIMPULAN DAN SARAN}

\section{Kesimpulan}

Berdasarkan hasil penelitian dan pembahasan yang telah dilakukan tentang pengaruh variasi produk terhadap keputusan pembelian bahan bangunan portal network six store cabang Depok, pada bab akhir ini penulis dapat menarik kesimpulan sebagai berikut :

Berdasarkan hasil analisis yang penulis lakukan, pengaruh variasi produk terhadap keputusan pembelian pada bahan bangungan Portal Network Six Store Cabang Depok dengan hasil uji koefisien korelasi ( $\boldsymbol{r}$ ) yaitu sebesar 0.6458. Hal ini menunjukan bahwa pengaruh variasi produk terhadap kepuatusan pembelian mempunyai pengaruh yang kuat dan positif. Sedangkan berdasarkan hasil koefisien determinasi variasi produk memiliki pengaruh terhadap keputusan pembelian sebesar $41.71 \%$ dan sisanya $58.29 \%$ di pengaruhi oleh faktor lain yang peneliti tidak lakukan kerana 
keterbatasan waktu, tenaga dan biaya. Di peroleh koefisien regresi : $Y=31,7$ + 0.5080X, yang berarti jika variasi produk naik 1 satuan maka akan meningkatkan keputusan pembelian sebesar 0,2843. Dan berdasarkan hasil uji hipotesis dengan nilai thitung $>t_{\text {tabel }}(8,2875>1,66088)$, maka $\mathrm{H}_{\circ}$ ditolak dan $\mathrm{H}_{\mathrm{a}}$ diterima, yang berarti terdapat pengaruh positif dan signifikan antara variasi produk $(X)$ terhadap Keputusan pembelian $(Y)$.

\section{Saran}

Berdasarkan analisa yang telah dilakukan dalam penelitian ini, maka penulis menyaranakan sebagai berikut:

1. Toko bangunan Portal Network Six Store cabang Depok harus lebih bisa menambakan ukuran yang bervariasi lagi agar konsumen dapat memilih produk yang diinginkan dan dibutuhkannya

2. Pilihan merek Toko bangunan Portal network Six Store cabang Depok harus lebih berkualitas lagi, agar konsumen tertarik dan dapat memilih produk yang sesuai dengan keinginan.

3. Toko bangunan portal network six store harus lebih bisa menambah lagi produknya khusunya ukuran yang bervariasi dan merek yang ada agar konsumen dapat memilih barang sesuai yang di inginkan dan butuhkan.

\section{DAFTAR PUSTAKA}

Ali Hasan. "Marketing dan Keputusan pembelian". Jakarta : Media Presindo 2009

Ali Sambas Muhidin dan Abdurrahman Maman,"Analisis Korelasi, Regresi, dan Jalur Dalam Penelitian", Pustaka Setia, Bandung ; 2009

Andri Feriyanto dan Endang Shyta Triana,"Pengantar Manajemen", Mediatera ,Kebumen ; 2015

Basu Swastha,"Manajemen Penjualan: Pelaksanaan Penjualan", BPFE, Yogyakarta ; 2010 
Bilson, Simamora "Memenangkan Pasar dengan Pemasaran Efektif dan Profitabel". Jakarta: PT. Gramedia Pustaka Utama 2011

Danang Sunyoto, “Dasar-dasar Manjemen Pemasaran”, CAPS, Yogyakarta ; 2012 Fandy Tjiptono, “Strategi Pemasaran", Edisi 2, Andy Offset, Yogyakarta ; 2009

Gunawan Adisaputro, "Manajemen Pemasaran (Analisis Untuk Perancangan Strategi Pemasaran)", Sekolah Tinggi IImu Manajemen YKPN, Yogyakarta ; 2010

Hasibun Malayu, "manajemen” Jakrta PT Bumi Askara 2012

Kotller dan keller, "Manajemen Pemasaran". Jilid I Edisi ke 13 erlangga Jakarta ; 2009

Kotler, Phillip dan Kevin Lane Keller. (2009). Manajemen Pemasaran edisi 13.

Pearson Education Inc. Upper Saddle River, New Jersey.

Philip Kotler dan Gary Armstrong, "Manajemen Pemasaran”, Edisi 12, Jilid 2, PT. Indeks, New Jersey ; 2017

Philip Kotler, "Manajemen Pemasaran" Edisi 13 Jakarta; Erlangga 2009

Schiffman Leon G dan Leslie L. Kanuk, "Perilaku Konsumen", PT. Indeks Gramedia, Jakarta ; 2008

Sugiyono, Metode Penelitian Kuantitatif, Kualitatif dan R\&D. Bandung: PT Alfabet. 2016

Sugiyono, "Metode Penelitian Kuantitatif Kualitatif dan R\&D”, Alfabeta, Bandung ; 2012

Suharno dan Yudi Sutarno, "Marketing in Practice”, Graha Ilmu, Yogyakarta ; 2010

Sunyato, Danang, “Dasar Dasar Manajemen Pemasaran”, Yogyakarta ; 2012

Vincent Gaspersz,"Total Quality Management", PT Gramedia Pustaka Utama, Jakarta ; 2015

http:Wikipedia.org/wiki/pemasaran

http://junaidochaniago.wordprees.com

http://www.jurnal.id/id/blog/pengertian-fungsi-unsur-unsur-manajemen

mu. 